\title{
Flexible-Screen-Printed Antenna with Enhanced Bandwidth by Employing Defected Ground Structure
}

\author{
Hattan F. Abutarboush, IEEE Member, Weiwei Li, and A. Shamim, IEEE Senior Member
}

\begin{abstract}
A flexible, wideband, and screen-printed antenna is proposed. The antenna is coplanar-waveguide (CPW) and composed of two inverted L-shape elements, a matching stub, and a defected ground structure (DGS), with a total area of $55 \times \mathbf{4 0} \times \mathbf{0 . 1 2 5} \mathbf{~ m m}$. Studies show that the DGS can significantly increase the antenna bandwidth from $30 \%$ to $119 \%$ without sacrificing the size. The antenna has a wide measured bandwidth of 1.77 - 6.95 GHz, and a measured peak gain and efficiency in the ranges of 2.5-5.9 $\mathrm{dBi}$ and $60 \%-90 \%$, respectively. Furthermore, both simulation and measurement confirm that the performance of the antenna is relatively stable under the bending conditions with various curvature radii.
\end{abstract}

Index Terms - Flexible antenna, Defected ground plane, Wideband antenna, 5G antenna, IoT, Screen printed antenna

\section{INTRODUCTION}

$\mathrm{U}$ SING cost-effective additive-manufacturing process to fabricate antennas has been attracted a great deal of interest among researchers and in electronic industries [1-10]. The advances of current wireless communication systems are targeting at the 5th generation (5G) systems, where wireless devices are able to communicate with each other like the Internet of things (IoT). As a result, designs of low-cost and flexible antennas for $5 \mathrm{G}$ devices of various shapes and sizes with wide bandwidths have attracted much attention [1119]. Flexible materials such as papers [8 - 10], polyethylene terephtalate (PET) [11], liquid crystal polymer (LCP) [12], thin glass [13], Kapton [14, 15] and Rogers [16, 17] have been proposed for uses in flexible antennas. However, these designs have either narrow bands or relatively large sizes. Some other designs have investigated the effects of bending only on the reflection coefficient $[11,16]$, while ignored the effects on the bandwidth, radiation pattern, gain and efficiency.

Monopole antenna has been widely studied and typically has narrow bandwidth. Different monopole designs have been reported to achieve multiple-band and wideband performances by employing various techniques such as using the shape of

Manuscript received April, 2020, revised July, 2020

Hattan F. Abutarboush is with the College of Engineering, Electrical Engineering Department, Taibah University, Madinah, P.O. BOX 344, Saudi Arabia. Weiwei $\mathrm{Li}$ and $\mathrm{A}$. Shamim are with the Computer, Electrical and Mathematical Sciences and Engineering (CEMSE) Division, King Abdullah University of Science and Technology (KAUST), Thuwal 23955-6900, Saudi Arabia. Email: Hattan.Abutarboush@ieee.org ground plane [20], E-shape slot [21], parasitic elements [22], metamaterial [23], periodical structures electromagnetic band gap (EBG) [24], and defected-ground structure (DGS) [19]. Study of DGS was started in 1999 [25], and then DGS had been used in various applications such as filters [26], microwave amplifiers [27] and antennas to improve the performances [28]. In antennas designs, DGSs usually used as resonators to create more bands or to disturb the currents on the radiators or the ground planes to enhance the bandwidths or gains. Recently, DGS has been used to produce multiband [29,30], notch band in an UWB antenna [31], high polarization isolation [32], reduction of coupling effects in MIMO antenna [33] and enhancements of antenna bandwidth [34 - 41]. However, the aforementioned antennas either had large sizes or limited bandwidths. The proposed antenna employs DGS to enhance the bandwidth without sacrificing the size. Table I compares the size and bandwidth of the proposed antennas with other antennas also employing DGS for bandwidth enhancement. The proposed antenna in this letter has the smallest overall size and second widest bandwidth with quite a low frequency. Moreover, the other reported antennas were designed on rigid substrates, which are not favorble for flexible applications.

In this paper, a flexible, wideband, compact and screen-printed antenna is proposed. The antenna employs a DGS to significantly enhanced the bandwidth from $30 \%$ to $119 \%$. The antenna is fabricated on a flexible Kapton substrate using a low-cost screen-printing technology. The proposed antenna has the advantages of low profile, simple structure, small size, cheap production, and without vias or lumped element components. The performance of the proposed antenna under different bending conditions is investigated using simulation and measurement.

TABLE I

COMPARISON WITH OTHER WORKS USING DGS FOR BANDWIDTH ENHANCEMENT*

\begin{tabular}{|c|c|c|c|c|}
\hline Ref. & $\begin{array}{c}\text { Total Size } \\
\text { L x W x H mm3 }\end{array}$ & $\begin{array}{c}\text { BW } \\
\text { Enhancement }\end{array}$ & Flexible? & $\begin{array}{c}\text { Lowest } \\
\text { Fre. GHz }\end{array}$ \\
\hline 34 & 345.6 & $140 \%$ & No & 3.09 \\
\hline 35 & 9200 & $112 \%$ & No & 0.7 \\
\hline 36 & 2190.4 & $80 \%$ & No & 2.23 \\
\hline 37 & 3556 & $>6.5 \%$ & No & 2.4 \\
\hline 38 & 1628.16 & $12.2 \%$ & No & 8 \\
\hline 39 & 133696.5 & $40.4 \%$ & No & 1.65 \\
\hline 40 & 987.55 & $56.67 \%$ & No & 9.8 \\
\hline 41 & 1638.4 & $40 \%$ & No & 6.48 \\
\hline Proposed & 275 & $119 \%$ & Yes & 1.77 \\
\hline
\end{tabular}

*ONLY DESIGNS OPERATING BELOW $10 \mathrm{GHZ} \mathrm{ARE} \mathrm{CONSIDERED}$ 


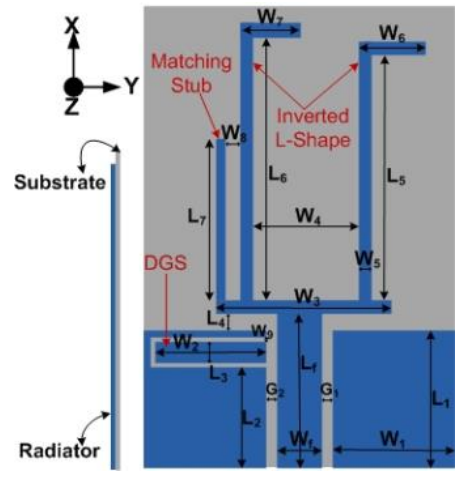

(a)

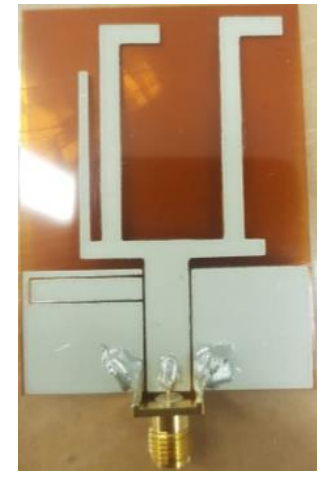

(b)
Fig. 1 (a) Geometry of the proposed antenna, and (b) prototype of the fabricated antenna

TABLE II

DIMENSIONS OF MAIN PARAMETERS OF PROPOSED ANTENNA (MM)

\begin{tabular}{|c|c|c|c|c|c|c|c|c|c|}
\hline $\mathrm{Lf}$ & $\mathrm{L}_{1}$ & $\mathrm{~L}_{2}$ & $\mathrm{~L}_{3}$ & $\mathrm{~L}_{4}$ & $\mathrm{~L}_{5}$ & $\mathrm{~L}_{6}$ & $\mathrm{~L}_{7}$ & $\mathrm{G}_{1}$ & $\mathbf{G}_{2}$ \\
\hline 19 & 17 & 12.5 & 3 & 2 & 29.5 & 30.5 & 25 & 0.5 & $\mathbf{0 . 5}$ \\
\hline $\mathrm{W}_{\mathrm{f}}$ & $\mathrm{W}_{1}$ & $\mathrm{~W}_{2}$ & $\mathrm{~W}_{3}$ & $\mathrm{~W}_{4}$ & $\mathrm{~W}_{5}$ & $\mathrm{~W}_{6}$ & $\mathrm{~W}_{7}$ & $\mathrm{~W}_{8}$ & $\mathrm{~W}_{9}$ \\
\hline 6 & 16.5 & 15.5 & 26 & 15 & 2.5 & 8.5 & 9 & $\mathbf{2}$ & $\mathbf{0 . 5}$ \\
\hline
\end{tabular}

\section{Antenna Design And Results}

\section{A. Layout of Antenna and Fabrication}

The design layout of the proposed flexible wideband screenprinted antenna is shown in Fig. 1(a), with key optimized dimensions listed in Table II. The antenna has a $50-\Omega$ Coplanar-wave-guide (CPW) feedline, a radiator with two inverted L-shape elements, a matching stub and a DGS. The radiator has an overall area of $55 \times 40 \mathrm{~mm} 2$. The two inverted L-shape elements act as monopoles to create multiple frequency bands. The matching stub is for matching (will be discussed later). The DGS is designed to enhance the antenna bandwidth. The substrate used is flexible Kapton material with a thickness of $125 \mu \mathrm{m}$, a relative permittivity of $\varepsilon r=3.5$ and a loss tangent of $\tan \delta=0.007$. The computer simulation tool, Ansoft HFSS software v18, has been used to study the performance of the antenna.

Our main objectives are to design a flexible and wideband antenna which can be fabricated using low-cost screen printing technique. We use CPW-feeding with only one layer of printing to avoid the possible misalignment between the top and bottom layers, as discussed in our earlier work [8,9]. Fabrication of the antenna is as follows. First, we deposit a layer of commercial silver ink (PE819 from DuPont) on a Kapton substrate through screen printing to form the radiator layer [1]. A mask of the antenna pattern as shown in Fig. 1(a) is cut using a $\mathrm{CO}_{2}$ laser system and placed on a blank screen mesh. After printing the silver traces, the antenna is heated at $120^{\circ} \mathrm{C}$ for $5 \mathrm{~min}$ to evaporate the solvents, which is followed by annealing in a vacuum oven at $150{ }^{\circ} \mathrm{C}$ for 1 hour. The ink layer has a conductivity $1.7 \times 107 \mathrm{~S} / \mathrm{m}$ with a thickness of approximately $4 \mu \mathrm{m}$. Finally, an SMA connector is mounted on the antenna using conductive epoxy and the final prototype of the antenna is shown in Fig 1(b).

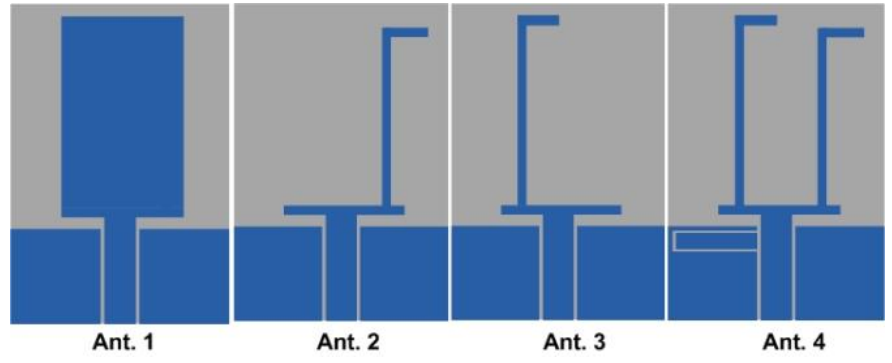

Fig. 2 Antennas used for analysis

Fig. 3: Simulated $S_{11}$ of the antenna using different parts

\section{B. Analysis of Proposed Antenna}

To analyse the operating mechanism of the proposed antenna, we use four antennas with the similar dimensions, as shown in Fig. 2, with the following studies and explanations.

1) Ant. 1 is a reference antenna. It is a $\lambda / 4$-monopole antenna designed to operate at around $2.6 \mathrm{GHz}$. The simulated $\mathrm{S}_{11}$ in Fig. 3 shows that it has an impedance bandwidth of only $30 \%$.

2) Ants. 2 and 3 have the right and left inverted L-shape elements, respectively, of the proposed antenna. Fig. 3 shows that both antennas have similar bandwidths, but the frequency band of $2.6-\mathrm{GHz}$ has been shifted to $1.7 \mathrm{GHz}$ with a narrower bandwidth and two weak bands are generated at about 5 and $6 \mathrm{GHz}$.

3) Ant 4 employs the DGS with both inverted L-shape elements. Fig. 3 shows that the bandwidth of the antenna has been improved, but the frequency range from 1.77 to $2.5 \mathrm{GHz}$ is not well matched.

4) The simulated $S_{11}$ of the proposed antenna with the matching stub added are compared in Fig. 3. It can be seen that the matching stub helps improve matching from 1.77 to $2.5 \mathrm{GHz}$. As a result, the antenna achieves a wideband from 1.77 to $6.95 \mathrm{GHz}$ with $119 \%$ bandwidth.

\section{Simulated and Measured $S_{11}$}

The simulated and measured $S_{11}$ of the proposed antenna is shown in Fig. 4. The result shows that, the antenna has an impedance bandwidth $\left(\mathrm{S}_{11}<-10 \mathrm{~dB}\right)$ of $1.77-6.95 \mathrm{GHz}$ or $119 \%$, which can cover most of the wireless and mobile applications as shown in Table III. The measured result of $S_{11}$ shows relatively good agreement with the simulation result. 
Fig. 4: Simulated and measured $S_{11}$ of proposed antenna

Table III

APPLICATIONS THAT CAN BE COVERED BY THE PROPOSED ANTENNA

\begin{tabular}{|c|c|c|c|c|c|}
\hline App. & $\begin{array}{l}\text { Freq. } \\
\text { GHz }\end{array}$ & App. & $\begin{array}{l}\text { Freq. } \\
\text { GHz } \\
\end{array}$ & App. & $\begin{array}{l}\text { Freq. } \\
\text { GHz } \\
\end{array}$ \\
\hline PCS & $\begin{array}{l}1.85- \\
1.99\end{array}$ & UMTS & 1.92-2.17 & $\begin{array}{c}\text { WLAN } \\
802.11 \\
\text { b/g/y }\end{array}$ & $2.4-2.484$ \\
\hline $\begin{array}{l}\text { GSM } \\
1800 \\
\end{array}$ & $\begin{array}{l}1.71- \\
1.88 \\
\end{array}$ & $\begin{array}{l}\text { LTE } \\
2300 \\
\end{array}$ & $2.305-2.4$ & $\begin{array}{l}\text { LTE } \\
2500\end{array}$ & $2.305-2.4$ \\
\hline $\begin{array}{c}\text { WiMAX } \\
\text { I } \\
\end{array}$ & 2.6-2.7 & $\begin{array}{c}\text { WiMAX } \\
\text { II }\end{array}$ & 3.4-3.69 & $\begin{array}{c}\text { WiMAX } \\
\text { III }\end{array}$ & $5.25-5.85$ \\
\hline S-DMB & $\begin{array}{l}2.63- \\
2.655\end{array}$ & $\begin{array}{c}\mathbf{5 G} \\
(\mathbf{N 7 7}) \\
\end{array}$ & $3.3-4.2$ & $\begin{array}{c}\mathbf{5 G} \\
(\mathbf{N 7 8}) \\
\end{array}$ & 3.3-3.8 \\
\hline $\begin{array}{c}\mathbf{5 G} \\
(\mathbf{N 7 9})\end{array}$ & 4.4-5 & $\begin{array}{c}\text { WLAN } \\
\text { IEEE 802.11 } \\
\text { a/n }\end{array}$ & $\begin{array}{c}(5.15 \\
-5.35) \\
\&(5.725- \\
5.825)\end{array}$ & $\begin{array}{c}\text { HiperLAN/ } \\
2\end{array}$ & $\begin{array}{c}5.470- \\
5.725\end{array}$ \\
\hline
\end{tabular}

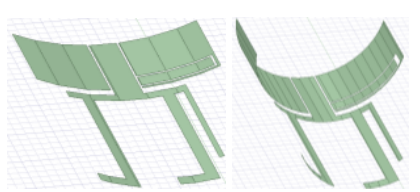

(a)

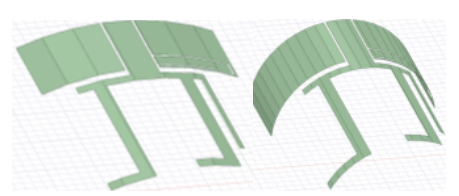

(c)

(d)
Fig. 5 Antenna models used in simulation for bending effect studies: (a)-(b) upper bending with $\mathrm{R}=50$ and $20 \mathrm{~mm}$, and (c)-(d) lower bending with $\mathrm{R}=-50 \mathrm{~mm}$ and $-20 \mathrm{~mm}$

\section{EFFECTS OF BENDING}

Here, we study the bandwidth and radiation pattern of the proposed antenna when it is bent in five bending curvature radii of $\mathrm{R}=50,20, \infty,-50$ and $-20 \mathrm{~mm}$, as shown in Figs. 5(a)(d), using computer simulation. While in measurements, we only select the conditions with more severe bending of $\mathrm{R}=-20$ and $20 \mathrm{~mm}$ for studies, as shown in Figs. 6(a)-(b). Note that when $\mathrm{R}$ is positive or negative, the antenna is bent upward or downward, respectively, and when $\mathrm{R}=\infty \mathrm{mm}$, the antenna is flat without bending.

\section{A. S11 and Impedance Bandwidth}

The simulated bandwidths of the antenna with flat, upper bending and lower bending are shown in Fig. 7(a). As a wide bandwidth is our target, the level of acceptability in terms of $\mathrm{S}_{11}$ has been defined to maintain the bandwidth of the antenna at flat state. It can be seen from Fig. 7(a) that bending has negligible effect on the performance of the antenna. Under all the bending conditions, the antenna has the bandwidth (with $\mathrm{S}_{11}<-10 \mathrm{~dB}$ ) from 1.77 to $6.95 \mathrm{GHz}(119 \%)$. The measured results in Fig. 7(b) show that bending with $R= \pm 20 \mathrm{~mm}$ also has

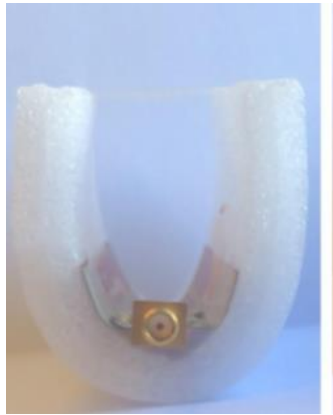

(a)

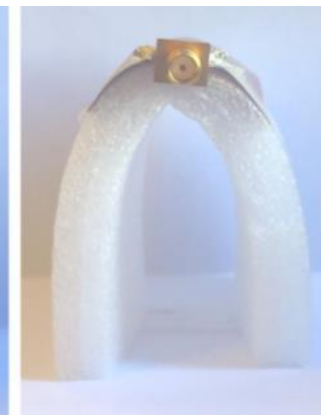

(b)
Fig. 6 Practical antenna used in measurements for bending effect studies: (a) upper bending with $\mathrm{R}=20 \mathrm{~mm}$, and (b) lower bending with $\mathrm{R}=-20 \mathrm{~mm}$. (b)

Fig. $7 \mathrm{~S}_{11}$ of the antenna with different curvature radii: (a) simulation with $\mathbf{R}= \pm \mathbf{2 0}$ and $\pm \mathbf{5 0} \mathbf{~ m m}$ and (b) measurement, as well as the simulated result with $\mathbf{R}$ $=+20 \mathrm{~mm}$ for comparison.

no significant effect on the bandwidth. The measured results in Fig. 7(b) indicate good agreements with the simulated results in 7(a). The simulated result for $\mathrm{R}=20 \mathrm{~mm}$ is added to Fig. 7(b) for comparison.

\section{B. Radiation Patterns, Gain and Efficiency}

The radiation patterns, gain, and efficiency of the proposed antenna with severe bending of $\mathrm{R}=20, \infty$, and $-20 \mathrm{~mm}$ are measured using the Satimo StarLab System at the King Abdullah University for Science and Technology (KAUST) $[42,43]$. As the antenna has a wide bandwidth of 1.77-6.95 $\mathrm{GHz}$, we select the frequencies of $2.4,3.5$, and $5.2 \mathrm{GHz}$ to study the radiation patterns. The measured E-field and $\mathrm{H}$-field for co-polarization in the $\mathrm{Y}-\mathrm{Z}$ and $\mathrm{X}-\mathrm{Z}$ planes at 2.4, 3.5, and 5.2 GHz are shown in Figs. 8(a)-(c). Fig. 8 shows that the unbent antenna has a monopole- shaped radiation pattern in the E-plane and nearly an omnidirectional radiation pattern in the H-plane. 
Fig. 8 Measured co-polarizations and simulated $\mathrm{x}$-polarizations in $\mathrm{Y}-\mathrm{Z}$ and $\mathrm{X}-\mathrm{Z}$ directions at (a) $2.4 \mathrm{GHz}$, (b) $3.5 \mathrm{GHz}$ and (c) $5.2 \mathrm{GHz}$ for flat and bent antennas with $R=+20 \mathrm{~mm}$

When the antenna is bent with $\mathrm{R}=20$ and $\mathrm{R}=-20 \mathrm{~mm}$, the radiation patterns are slightly affected, as shown in Fig. 8. Some energies are lost from one side of the antenna, but is gained in other side with no null in the broadside direction. The simulated x-polarization for the flat antenna is also shown in Figs. 8(a)-(c). Results have also shown that the bending has insignificant effect on the $\mathrm{x}$-polarization component. For brevity, the results are not included.

The simulated and measured peak gains and efficiencies of the antenna with flat, upper bending and lower bending are shown in Fig. 9 (a)-(b) for better comparison. It can be seen that all the results follow similar trends in gain with a range of 2.5-5.9 $\mathrm{dBi}$. The maximum difference between the simulated and measured results is about $1.5 \mathrm{~dB}$ as shown in Fig. 9(a). For efficiency, the maximum difference between the simulated and measured results is about $25 \%$ for the flat, upper bending and lower bending as shown in Fig. 9 (b). (a)

(b)

Fig. 9: Simulated and measured (a) gains and (b) efficiencies of antenna with flat and $R= \pm 20 \mathrm{~mm}$

\section{CONCLUSIONS}

A wideband and flexible antenna fabricated using low-cost screen printing technique has been proposed. The antenna is composed of two inverted L-shape elements, matching stub, and DGS, with a total size of $55 \times 40 \times 0.125 \mathrm{~mm} 3$. Studies have shown that the DGS can increase the bandwidth from $30 \%$ to $119 \%$. As a result, the antenna achieves a bandwidth of 1.77$6.95 \mathrm{GHz}$ and hence it is suitable for various wideband communication systems, especially working in the sub $7 \mathrm{GHz}$ bands, such as the $5 \mathrm{G}$ applications. Both the simulated and measured results have shown that the performance of the proposed antenna under different bending conditions is relatively stable. The antennas have the advantages of small size, low profile, simple configuration, and low cost for mass production, which make it a promising design for upcoming compact, slim, and flexible mobile and wireless devices. Future work will be considered to study the proposed antenna when it is bent in the $\mathrm{y}$-direction rather than only the $\mathrm{x}$ direction.

\section{REFERENCES}

[1] A. Meredov, K. Klionovski, and A. Shamim, "Screen-Printed, Flexible, Parasitic Beam-Switching Millimeter-Wave Antenna Array for Wearable Applications," IEEE Open Journal of Antennas and Propagation, vol. 1, pp. 2-10, 2020.

[2] M. F. Farooqui, C. Claudel, and A. Shamim, "An Inkjet-Printed Buoyant 3-D Lagrangian Sensor for Real-Time Flood Monitoring," IEEE Transactions on Antennas and Propagation, vol. 62, no. 6, pp. 33543359, 2014.

[3] S. Kim, A. Shamim, A. Georgiadis, H. Aubert, and M. M. Tentzeris, "Fabrication of Fully Inkjet-Printed Vias and SIW Structures on Thick Polymer Substrates," IEEE Trans. Compon. Packag. Manuf. Technol., vol. 6, no. 3, pp. 486-496, 2016. 
[4] A. Quddious et al., "Disposable, Paper-Based, Inkjet-Printed Humidity and $\mathrm{H}_{2} \mathrm{~S}$ Gas Sensor for Passive Sensing Applications," (in eng), Sensors (Basel, Switzerland), vol. 16, no. 12, p. 2073, 2016.

[5] A. Maza, B. Cook, G. Jabbour, and A. Shamim, "Paper-based inkjetprinted ultra-wideband fractal antennas," IET Microwaves, Antennas and Propagation, vol.6, no.12, pp.1366-1373, 2012.

[6] B. Tehrani, B. Cook and M. Tentzeris, "Inkjet Printing of Multilayer Millimeter-Wave Yagi-Uda Antennas on Flexible Substrates," in IEEE Antennas and Wireless Propagation Letters, vol.15, pp.143-146, 2016.

[7] H. Khaleel, "Design, Fabrication and Testing of Flexible Antennas," 2012.

[8] H. F. Abutarboush, M. Farooqui and A. Shamim, "Inkjet-Printed Wideband Antenna on Resin-Coated Paper Substrate for Curved Wireless Devices," IEEE Antennas and Wireless Propagation Letters, vol.15, pp.20-23, 2016.

[9] H. F. Abutarboush, A. Shamim, "Paper-Based Inkjet-Printed Tri-Band U-Slot Monopole Antenna for Wireless Applications," IEEE Antennas and Wireless Propagation Letters, vol.11, pp.1234-1237, 2012.

[10] H. F. Abutarboush and A. Shamim, "Wide frequency independently controlled dual-band inkjet-printed antenna," in IET Microwaves, Antennas and Propagation, vol. 8, no. 1, pp. 52-56, 2014.

[11] D. Betancourt, J. Castan, "Printed Antenna on Flexible Low-Cost PET Substrate for UHF Applications," Progress in Electromagnetics Research C, Vol. 38, 129-140, 2013.

[12] L. Marnat, A. Shamim, "Liquid Crystal Polymer (LCP) based antenna for flexible system on package (SoP) applications," 15th International Symposium on Antenna Technology and Applied Electromagnetics (ANTEM), pp.1-4, 25-28 June 2012.

[13] S. Hong, S. H. Kang, Y. Kim and C. W. Jung, "Transparent and Flexible Antenna for Wearable Glasses Applications," in IEEE Transactions on Antennas and Propagation, vol. 64, no. 7, pp. 2797-2804, July 2016.

[14] S. Ahmed, F. Tahir, A. Shamim, and H. Cheema, "A Compact KaptonBased Inkjet-Printed Multiband Antenna for Flexible Wireless Devices," IEEE Antennas and Wireless Propagation Letters, vol. 14, pp. 1802$1805,2015$.

[15] H. R. Khaleel, H. M. Al-Rizzo, and D. G. Rucker, "Compact polyimidebased antennas for flexible displays," Journal Display Technol., vol. 8, no. 2, pp. 91-97, Feb. 2012.

[16] M. O. Sallam, S. M. Kandil, V. Volski, G. A. Vandenbosch, and E. A. Soliman, "Wideband CPW-fed flexible bow-tie slot antenna for WLAN/WiMax systems," IEEE Transactions on Antennas and Propagation, vol. 65, no. 8, pp. 4274-4277, 2017.

[17] H. Liu, P. Wen, S. Zhu, B. Ren, X. Guan and H. Yu, "Quad-Band CPWFed Monopole Antenna Based on Flexible Pentangle-Loop Radiator," IEEE Antennas and Wireless Propagation Letters, vol.14, pp.1373-1376, 2015.

[18] Y. U. Devi, M. Rukmini, and B. Madhav, "Liquid crystal polymer based flexible and conformal 5G antenna for vehicular communication," Material Research Express, vol. 6, no. 1, p. 016306, 2018.

[19] S. F. Jilani, A. K. Aziz, Q. H. Abbasi and A. Alomainy, "Ka-band Flexible Koch Fractal Antenna with Defected Ground Structure for 5G Wearable and Conformal Applications," 2018 IEEE 29th Annual International Symposium on Personal, Indoor and Mobile Radio Communications (PIMRC), Bologna, pp. 361-364, 2018.

[20] K. Wong, W. Chen, L. Chou and M. Hsu, "Bandwidth Enhancement of the Small-Size Internal Laptop Computer Antenna Using a Parasitic Open Slot for Penta-Band WWAN Operation," in IEEE Transactions on Antennas and Propagation, vol. 58, no. 10, pp. 3431-3435, Oct. 2010.

[21] H. F. Abutarboush, H. Nasif, R. Nilavalan and SW Cheung, "Multiband and Wideband Monopole Antenna for GSM900 and Other Wireless Applications," in IEEE Antennas and Wireless Propagation Letters, vol.11, pp.539-542, 2012.

[22] XL Sun, SW Cheung and TI Yuk, "Dual-Band Antenna with Compact Radiator for 2.4/5.2/5.8 GHz WLAN Applications", IEEE Transactions on Antennas and Propagation, pp. 5924-5931, 2012.

[23] J. K. Ji, G. H. Kim and W. M. Seong, "Bandwidth Enhancement of Metamaterial Antennas Based on Composite Right/Left-Handed Transmission Line," in IEEE Antennas and Wireless Propagation Letters, vol. 9, pp. 36-39, 2010.

[24] S. Kim, R. Yu-Jiun, L. Hoseon, A. Rida, S. Nikolaou, M. Tentzeris, "Monopole Antenna with Inkjet-Printed EBG Array on Paper Substrate for Wearable Applications," IEEE Antennas and Wireless Propagation Letters, vol.11, pp.663,666, 2012.

[25] Khandelwal, M.K.; Kanaujia, B.K.; Kumar, S. "Defected ground structure: Fundamentals, analysis, and applications in modern wireless trends". International Journal of Antennas and Propagation, Vo.2017, ID:2018527, 2017.

[26] D. Ahn, J.-S. Park, C.-S. Kim, J. Kim, Y. Qian, and T. Itoh, "A design of the low-pass filter using the novel microstrip defected ground structure," IEEE Transactions on MicrowaveTheory and Techniques, vol. 49, no. 1, pp. 86-93, 2001.

[27] H.-J. Choi, J.-S. Lim, and Y.-C. Jeong, "A new design of Doherty amplifiers using defected ground structure," IEEE Microwave and Wireless Components Letters, vol. 16, no. 12, pp. 687 689, 2006.

[28] M. A. Antoniades and G. V. Eleftheriades, "A Compact Multiband Monopole Antenna with a Defected Ground Plane," in IEEE Antennas and Wireless Propagation Letters, vol. 7, pp. 652-655, 2008.

[29] A. K. Gautam, L. Kumar, B. K. Kanaujia and K. Rambabu, "Design of Compact F-Shaped Slot Triple-Band Antenna for WLAN/WiMAX Applications," in IEEE Transactions on Antennas and Propagation, vol. 64, no. 3, pp. 1101-1105, 2016.

[30] J. Pei, A. Wang, S. Gao, and W. Leng, "Miniaturized triple band antenna with a defective ground plane for WLAN/WiMAX applications," IEEE Antennas and Wireless Propagation Letters, vol.10, pp.298-301, 2011.

[31] A. Sarma, K. Sarmah, S. Goswami, K. K. Sarma and S. Baruah, "DGS based planer UWB antenna with band rejection features," International Conference on Wireless Communication, Signal Processing and Networking (WiSPNET), Chennai, pp. 2640-2644, 2017.

[32] S. Chakraborty, A. Ghosh, S. Chattopadhyay and L. L. K. Singh, "Improved Cross-Polarized Radiation and Wide Impedance Bandwidth from Rectangular Microstrip Antenna With Dumbbell-Shaped Defected Patch Surface," in IEEE Antennas and Wireless Propagation Letters, vol. 15, pp. 84-88, 2016

[33] A. B. Numan, M. S. Sharawi, A. Steffes and D. N. Aloi, "A defected ground structure for isolation enhancement in a printed MIMO antenna system," 7th European Conference on Antennas and Propagation (EuCAP), Gothenburg, pp. 2123-2126, 2013.

[34] N. Ojaroudi, "Compact UWB monopole antenna with enhanced bandwidth using rotated L-shaped slots and parasitic structures," Micr. and Optical Technology Letters, vol. 56, no. 1, pp. 175-178, 2014.

[35] K. H. Chiang and K. W. Tam, "Microstrip monopole antenna with enhanced bandwidth using defected ground structure," IEEE Antennas Wireless Propagation Letters, vol. 7, pp. 532-535, 2008.

[36] Y. Sung, "Bandwidth enhancement of a microstrip line-fed printed wideslot antenna with a parasitic center patch," IEEE Transactions on Antennas and Propagation, vol. 60, no. 4, pp. 1712-1716, 2012.

[37] B. R. S. Reddy and D. Vakula, "Compact Zigzag-Shaped-Slit Microstrip Antenna With Circular Defected Ground Structure for Wireless Applications," in IEEE Antennas and Wireless Propagation Letters, vol. 14, pp. 678-681, 2015.

[38] Kandwal, A, Rakesh S, and Sunil K. K., "Bandwidth Enhancement Using Z-Shaped Defected Ground Structure for a Microstrip Antenna." Microwave and Optical Technology Letters 55.10 (2013): 2251-2254.

[39] M. M. Ulfah, Chairunrrisa, A. H. Wahyudi and A. Munir, "Slot and DGS Incorporation for Bandwidth Enhancement of Substrate Integrated Waveguide Antenna," Progress in Electromagnetics Research Symposium, Toyama, pp. 1838-1841, 2018.

[40] M. K. Khandelwal, B. K. Kanaujia, S. Dwari and S. Kumar, "Design and analysis of microstrip DGS patch antenna with enhanced bandwidth for $\mathrm{Ku}$ Band applications," International Conference on Microwave and Photonics (ICMAP), Dhanbad, pp. 1-4, 2013.

[41] J. A. Ansari, S. Verma, M. K. Verma, and N. Agrawal, "A Novel Wide Band Microstrip-Line-Fed Antenna with Defected Ground for CP Operation," Prog. In Electrom. Research C, Vol. 58, 169-181, 2015.

[42] Z. Su, K. Klionovski, R. M. Bilal, and A. Shamim, "A Dual Band Additively Manufactured 3-D Antenna on Package With Near-Isotropic Radiation Pattern," IEEE Trans. Antennas Propag., vol. 66, no. 7, pp. 3295-3305, 2018.

[43] H. Liao, Q. Zhang, M. Karimi, Y. Kuo, N. Mishra, and A. Shamim, "An Additively Manufactured 3D Antenna-in-Package with Quasi-Isotropic Radiation for Marine Animals Monitoring System," IEEE Antennas and Wireless Propagation Letters, vol. PP, pp. 1-1, 08/26 2019. 